\title{
ASSOCIATION BETWEEN OXYTOCIN USE DURING DILATION AND EVACUATION AND ESTIMATED BLOOD LOSS
}

\author{
A THESIS SUBMITTED TO THE GRADUATE DIVISION OF THE \\ UNIVERSITY OF HAWAI'I AT MĀNOA IN PARTIAL FULFILLMENT \\ OF THE REQUIREMENTS FOR THE DEGREE OF \\ MASTER OF \\ BIOMEDICAL SCIENCE
}

AUGUST 2015

By

Katherine C. Whitehouse

Thesis Committee:

Bliss Kaneshiro, Chairperson

Rosanne Harrigan

James Davis

Keywords: abortion, dilation and evacuation, oxytocin, hemorrhage 


\section{TABLE OF CONTENTS:}

1. Abstract.................... 3

2. Introduction................4

3. Materials...................5

4. Results................... 7

5. Discussion.................10

6. List of Tables..............13

Table 1..............14

Table 2...............16

Table 3.............. 18

Table 4................19

7. References................20 


\begin{abstract}
Objectives: Many providers use oxytocin during dilation and evacuation (D\&E) to prevent or treat hemorrhage. Evidence to support this practice is scarce. We sought to describe the association between oxytocin use, estimated blood loss (EBL), and surgical outcomes during D\&E.
\end{abstract}

Study Design: Women undergoing D\&E ( $\geq 14$ weeks) between 2010 and 2014 were included in this retrospective cohort study to assess the association between oxytocin use and EBL. We also determined whether sociodemographic and health-related factors were associated with higher EBL and whether oxytocin use was associated with a lower complication rate. Mean EBL was compared with a t-test. Excessive blood loss, defined as EBL at or above $250 \mathrm{ml}$, demographics, and complications were compared with a chi-square and Fisher's Exact tests. Logistic regression was performed. Our database, which included 649 women undergoing D\&E, had the ability to detect a $7.5 \%$ difference in excessive blood loss.

Results: Oxytocin was used in $68.3 \%$ of the procedures. Asian $(p=0.02)$ and Native Hawaiian/Pacific Islander $(p=0.03)$ race, abortion indication $(p=0.008)$ and higher gestational age $(p<0.001)$ were associated with oxytocin use. Mean EBL [133.1 (sd $=133.9) \mathrm{ml}$ versus $105 \mathrm{ml}(73.8), p<0.001]$ and excessive blood loss $(11.1 \%$ vs. $4.9 \%$, $p=0.01$ ) were higher in the oxytocin group. No significant difference in complication rates emerged ( $4.7 \%$ with oxytocin vs. $4.4 \%$ without, $p=0.579$ ). The adjusted OR for excessive blood loss was $1.61(95 \% \mathrm{Cl} 0.77,3.77)$ when women received oxytocin.

Conclusions: Oxytocin use during D\&E did not have a significant association with surgical outcomes including EBL and complications in our population.

Implications: Routine use of interventions for bleeding, such as intravenous oxytocin, should be based on scientific evidence or not performed. Findings from our study provide information on how oxytocin use is associated with blood loss during D\&E. 


\section{INTRODUCTION}

Nearly 1.06 million abortions are performed in the United States each year, making it one of the most common surgical procedures undertaken [1]. Only a small number of surgical abortions, 1.9 per 1000 procedures, result in a complication [2, 3]. Hemorrhage, defined as blood loss over 250 to $500 \mathrm{~mL}$ [4], occurs in $0.8 \%$ to $2.1 \%$ of all dilation and evacuation (D\&Es) procedures and is the most common complication of $D \& E[4,5]$. The rate of hemorrhage increases with gestational age; as many as $6.3 \%$ of D\&Es performed above 18 weeks gestation are affected by hemorrhage [6].

In an attempt to decrease blood loss and hemorrhage at the time of D\&E, many abortion providers routinely administer prophylactic uterotonics, like oxytocin [7]. Little research exists to support this practice. The ability of oxytocin to decrease bleeding is extrapolated from the obstetric literature where it is used at the time of term delivery. Many have hypothesized that oxytocin has little effect in the late second and early third trimesters. Oxytocin receptor concentration does not increase significantly until approximately 37 weeks gestation and receptors are not fully expressed until labor begins $[8,9]$. Studies evaluating routine oxytocin for first-trimester surgical abortion did not show any change in blood loss $[10,11]$. To date, no studies have evaluated routine oxytocin administration at the time of second trimester surgical abortion. We seek to evaluate the association between oxytocin use and estimated blood loss (EBL) and surgical outcomes during D\&E. 


\section{MATERIAL AND METHODS}

We performed a retrospective cohort study on women who underwent a D\&E in Honolulu, Hawaii. We examined whether intravenous oxytocin use was EBL and complications. We also explored whether sociodemographic or health-related factors were associated with EBL. Data were obtained from a pre-existing abortion database, which included de-identified patient information from all abortion procedures performed at our institution from 2010 to 2014 . The database was created after investigators received institutional review board (IRB) approval from Western IRB with authority ceded by University of Hawaii Human Studies Program. Data was extracted from electronic medical records.

Inclusion criteria included all subjects who had a D\&E procedure at 14 weeks gestation or greater for any indication including induced abortion, fetal anomaly, fetal demise, or preterm premature rupture of membranes). We excluded subjects with molar pregnancies and those who were missing integral data on oxytocin use. A subject could be included in the database twice if she underwent two D\&Es during the study period. Gestational age was confirmed with ultrasound for all pregnancies.

According to standard-of-care at our institution, all D\&E subjects underwent preoperative cervical dilation with laminaria approximately 24 hours prior to procedure and received prophylactic antibiotics. Six experienced D\&E providers, as well as directly supervised Family Planning fellows and OB/GYN residents, performed all procedures. Anesthetic regimens were chosen by experienced anesthesiologists and included moderate sedation or general anesthesia.

To determine whether subjects were exposed to oxytocin during D\&E, we examined operative reports, anesthesia notes, and medication administration records. These records did not indicate if oxytocin was used prophylactically or as an intervention for heavy bleeding nor did they indicate the exact dose received. Intraoperative blood loss was based on provider estimates and recoded in operative 
reports. Operative complications such as uterine perforation, infection, cervical laceration, or need for additional procedures was extracted from patient charts. We also identified subjects with follow-up complications based on subsequent office or emergency department visits found to occur in the chart after the surgical encounter.

Data were analyzed with SAS (Statistical Analysis System) software version 9.3 and $R$ software version 3.0.3. Continuous demographic variables and mean and median EBL were compared with a students t-test and Wilcoxon test, respectively. Categorical demographic variables, EBL greater than or equal to $250 \mathrm{~mL}$, and complications were compared with chi-square and Fisher's exact tests. Logistic regressions was performed. For our study outcome, rate of $E B L \geq 250 \mathrm{~mL}$, we estimated a baseline rate of $15 \%$ based on a recently published study by Micks et al [12]. They report a rate of $E B L>250 \mathrm{~mL}$ of $15 \%$ in D\&E patients exposed to inhaled anesthetics, which is common practice at our site; their unexposed group had a rate of

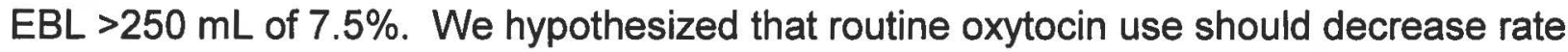
of $E B L \geq 250 \mathrm{~mL}$ by $7.5 \%$. Our database had the ability to detect a $7.5 \%$ difference in $E B L \geq 250 \mathrm{~mL}$ with an alpha of 0.05 and a beta of 0.20 . A p-value $\leq 0.05$ was considered statistically significant. 


\section{RESULTS}

From May 2010 to May 2014, a total of 685 underwent a D\&E at 14 weeks gestation or above. Thirty-five subjects were excluded due to missing data about oxytocin use and one subject with a molar pregnancy was excluded. In our study population, $68.3 \%$ were exposed to oxytocin during D\&E. The mean age was 25.4 \pm 6.79 years. Our population was composed of a large percentage of women who selfidentified as Native Hawaiian/Pacific Islander race (42.5\%), with the next most prevalent races being Asian (39.3\%) and white (16.9\%). The majority of our population had one to four prior deliveries $(57.2 \%)$ and $38.5 \%$ were nulliparous. Seventy-three percent of our study population had undergone at least one abortion in the past. The mean gestational age at the time of D\&E was 18 weeks and 0 days \pm 16 days. The majority of subjects were 14 to 22 weeks gestation, with only seven procedures (1.1\%) occurring past 22 weeks. The most common indication for D\&E was "induced abortion" (87.8\%), with the remaining $12.2 \%$ for indications of fetal anomaly $(9.1 \%)$, fetal demise $(2.9 \%)$, or premature preterm rupture of membranes $(0.2 \%)$. Only $26.2 \%$ of our population returned for post-D\&E follow-up visits.

Sociodemographic factors were compared between subjects exposed versus unexposed to oxytocin and is shown in Table 1. We found no significant difference between age, parity, prior obstetrical or abortion history, incidence of multiple gestations, and follow-up rates between groups. The probability of being exposed to oxytocin was significantly higher for those of Asian $(p=0.02)$ or Native Hawaiian/Pacific Islander $(p=0.03)$ race. Mean time since last delivery was significantly longer in the oxytocin group at $14.3 \pm 4.5$ versus $12.6 \pm 4.8$ months $(p<0.001)$. Gestational age was significantly higher in the oxytocin group at a mean of 18 weeks and 3 days \pm 16 days versus 17 weeks and 0 days \pm 14 days in the unexposed group $(p<0.001)$. Preoperative diagnosis for $D \& E$ differed significantly between the exposed and unexposed groups $(p=0.008)$. 
Table 2 describes the association between sociodemographic factors and estimated blood loss. Mean EBL in our overall population was $124.2 \pm 118.1 \mathrm{~mL}$; only $9.1 \%$ had an EBL greater than or equal to $250 \mathrm{~mL}$. A total of 10 subjects $(1.5 \%)$ had an EBL greater than or equal to $500 \mathrm{~mL}$. We found a statistically significant difference in both median (100 [20-600] mL vs. 100 [5-1500] mL, $p<0.001)$ and mean EBL $(105 \pm 73.8$ $\mathrm{mL}$ vs. $133.1 \pm 133.9 \mathrm{~mL}, \mathrm{p}=0.004$ ) between the unexposed and exposed groups. We also identified a significant difference in the rate of $E B L \geq 250 \mathrm{~mL}, 11.1 \%$ in oxytocin group had an EBL $\geq 250 \mathrm{~mL}$ versus $4.9 \%$ in the unexposed group ( $p=0.01$ ); there was no significant difference in the rate of EBL above 500 . Subjects who self-identified as white race had a significantly lower mean EBL $(109.7 \pm 75.5 \mathrm{~mL})$ compared to all other races. Otherwise, race, parity, history of cesarean section, preoperative diagnosis, or presence of multiple gestations had no significant association with differences in mean $E B L$ or rate of $E B L \geq 250 \mathrm{~mL}$. Advancing gestational age was significantly associated with higher mean EBL and rate of $E B L \geq 250 \mathrm{~mL}(p<0.001) ; 20.4 \%$ of those at 20 weeks of gestation or above had an $\mathrm{EBL} \geq 250 \mathrm{~mL}$.

In Table 3 we describe rates of intraoperative complications as well as complications identified at follow-up visits between the exposed and unexposed groups. Thirty intraoperative complications $(4.6 \%)$ occurred in our population: two uterine perforations, 14 hemorrhages (defined as EBL $\geq 500 \mathrm{ml}$ or provider documentation of hemorrhage), five cervical lacerations, one repeat suction procedure, and three "other" complications which included premature rupture of membranes, sigmoid mesenteric laceration and broad ligament hematoma (both due to cases of uterine perforation). We found no significant difference in complication rates between groups. A total of five complications were identified at follow-up encounters $(0.77 \%)$. Follow-up complications included the following: one emergency department visit for severe postoperative nausea and vomiting, four cases necessitating a repeat uterine evacuation, and one late identification of uterine perforation. We identified a significantly higher number of followup complications in the unexposed group at $1.94 \%$ vs. $0.23 \%(p=0.025)$, however only $26.2 \%$ of our population returned for follow-up overall. In combining both intraoperative 
and follow-up complications, an overall complication rate of $5.4 \%$ existed in our population.

Logistic regression was performed (Table 4) to further assess the relationship between oxytocin use and higher blood loss (i.e. EBL $\geq 250 \mathrm{~mL}$ ). The following potential confounders were initially included in the model: race, parity, months since last delivery, gestational age, preoperative diagnosis, cesarean section history, and multiple gestations. Using backwards selection, we found that gestational age was the only variable significantly associated with a likelihood for higher EBL thus we adjusted for only gestational age and oxytocin use in our final model. For every increasing week of gestational age, in our population, there was a higher chance for increased $E B L \geq 250$ $\mathrm{mL}$ (AOR 1.31, 95\% Cl 1.15-1.50, $\mathrm{p}<0.001$ ). When stratified by gestational age groups, we further identified populations with higher likelihood for increased EBL. Those with gestational age of 18 weeks and above have higher likelihood $E B L \geq 250 \mathrm{~mL}$ with an AOR of $2.47,95 \% \mathrm{Cl} 1.34-4.53$ ( $p=0.004$ ). Stratifying by two week gestational age increments also demonstrated that increasing gestational age, particularly at 20 weeks and above, was associated with higher EBL: AOR 1.58, 95\% $\mathrm{Cl} 0.56-4.48$ at 16 - 18 weeks, AOR $1.37,95 \% \mathrm{Cl} 0.47-3.97$ at $18-20$ weeks, and OR $5.46,95 \% \mathrm{Cl} 2.15$ $13.87(p<0.001)$ at $20+$ weeks gestation. The adjusted $O R$ for $E B L \geq 250$ was $1.61,95 \%$ $\mathrm{Cl}$ 0.77-3.37, when subjects received oxytocin. 


\section{DISCUSSION}

Our study examined whether women who were exposed to intravenous oxytocin during D\&E demonstrated a difference in estimated blood loss or complication rates compared to those who did not. To date, no prior studies have evaluated the relationship between oxytocin use and bleeding outcomes at the time of second trimester surgical abortion. The majority of our study population was exposed to oxytocin, at a rate of $68.3 \%$. Providers were more likely to use oxytocin on subjects with higher gestational age, in fact, $100 \%$ of subjects at 22 weeks and above received oxytocin. Although our database did not provide the indication for oxytocin use (i.e. prophylactic vs. therapeutic), because the rate of hemorrhage was only $2.2 \%$, we can assume that oxytocin was primarily used prophylactically in our population.

While we did find a statistically significant difference in mean EBL between groups (105 $\pm 73.8 \mathrm{~mL}$ without oxytocin vs. $133.1 \pm 133.9 \mathrm{~mL}$ with oxytocin), this amount is not clinically relevant. Overall rates of higher $E B L(\geq 250 \mathrm{~mL}$ ) were low at $9.1 \% \geq 250$ $\mathrm{mL}$ and $1.5 \% \geq 500 \mathrm{~mL}$. The rate of EBL $\geq 250 \mathrm{~mL}$ was significantly higher in the oxytocin group at $11.1 \%$ (vs. $4.9 \%$ ), likely due to the fact that oxytocin was used prophylactically in higher gestational ages D\&Es and was given as a treatment for heavy bleeding, not because oxytocin inherently caused more bleeding. In our study population, advancing gestational age was the only factor significantly related to higher EBL. There is a 2.5 -fold greater chance for higher EBL at 18 weeks and above compared to less than 18 weeks. At 20 weeks and above, there is a 5.5-fold higher chance for higher EBL compared to gestations of 14 to 16 weeks.

In the literature, complications during D\&E are generally reported to be less than $1 \%[2,3]$. Our rate of overall complications was higher at $5.4 \%$, however some of these complications such as representation to the emergency department for vomiting and premature rupture of membranes, were not very morbid complications. Our overall rate of hemorrhage (defined as $E B L \geq 500 \mathrm{ml}$ or provider documentation of hemorrhage) was 
consistent with previously reported rates at $2.2 \%[4,5]$. Complication rates did not differ between the oxytocin and unexposed groups. Based on our data, use of oxytocin during D\&E does not appear to have significant relationship to blood loss and patient outcomes.

Our study is strengthened by its large sample size and diverse demographics. Our population was unique in that it included a large number (42.5\%) of Native Hawaiian/Pacific Islanders. Because this study took place at a teaching institution, residents and fellows were involved in many of the procedures making results generalizable to an academic institution. Currently, only one study reports median blood loss with D\&E [12]. Our study adds to the literature on this topic to better guide providers on what the blood loss and rate of hemorrhage is during D\&E. Our data may also guide providers to exercise caution when performing D\&E's at 18 to 20 weeks and above because the risk of higher EBL is much more likely in those populations.

The optimal study exploring interventions to decrease blood loss at the time of D\&E would use hemorrhage, defined as blood loss above $500 \mathrm{~mL}$ as the primary outcome and would use a randomized-controlled methodology. Because the rate of hemorrhage with D\&E ranges between 0.8 and $2.1 \%$, our database was not large enough to demonstrate significant differences in that outcome and a prospective, randomized-controlled study would not be feasible [4-6]. Given the retrospective nature of our database, we were unable to determine whether oxytocin was administered prophylactically or as a treatment for higher than expected bleeding. We were unable to accurately ascertain the number of units of oxytocin administered, the time at which the medication was started, and the overall operative time. We were also unable to control for preoperative use of misoprostol, intraoperative ultrasound guidance, and whether or not trainees were involved. The blood loss recorded in our database is estimated, not measured, therefore the accuracy of these amounts relies on provider's ability to visually assess blood loss. Though this is the most common way to assess bleeding with all surgical procedures, it may be subject to bias. 
At least 100,000 D\&Es are performed in the United States each year [13, 14]. While D\&E has a low risk for major complications, refinement of the procedure is necessary $[4,5]$. Routine use of interventions, such as intravenous oxytocin, should be based on scientific evidence or be abandoned. Findings from this retrospective study suggest that oxytocin use is not associated with blood loss during D\&E. Clinical trials are needed to directly address the effect of oxytocin on blood loss during D\&E and are currently ongoing out our institution. The role of uterotonics in both preventing and treating heavy blood loss during D\&E still requires additional research attention so that women may receive abortions under the safest of conditions. 


\section{LIST OF TABLES:}

1. Baseline characteristics of women undergoing D\&E by oxytocin use

2. Baseline characteristics and estimated blood loss

3. Complications related to oxytocin use

4. Logistic Regression: Relationship between gestational age \& $E B L \geq 250 \mathrm{ml}$ 
Table 1: Baseline characteristics of women undergoing D\&E by oxytocin use

\begin{tabular}{|c|c|c|c|c|}
\hline & Total & No Oxytocin & Oxytocin & P-value \\
\hline & $\mathrm{N}=649$ & $\mathrm{~N}=206(31.7 \%)$ & $\mathrm{N}=443(68.3 \%)$ & \\
\hline Age (mean) & 25.4, SD 6.79 & 25.3 SD 6.3 & 25.5 SD 7.0 & 0.651 \\
\hline \multicolumn{5}{|l|}{ Race } \\
\hline Asian & $255(39.3 \%)$ & $67(32.5 \%)$ & $188(42.4 \%)$ & 0.02 \\
\hline Native $\mathrm{HI} / \mathrm{Pac}$ Is & $276(42.5 \%)$ & $101(49 \%)$ & $175(39.5 \%)$ & 0.03 \\
\hline Black & $14(2.2 \%)$ & $8(3.9 \%)$ & $6(1.4 \%)$ & 0.076 \\
\hline White & $110(16.9 \%)$ & $31(15 \%)$ & $79(17.8 \%)$ & 0.443 \\
\hline Unk/Other & $26(4 \%)$ & $11(5.3 \%)$ & $15(3.4 \%)$ & 0.81 \\
\hline \multicolumn{5}{|l|}{ Parity } \\
\hline 0 & $250(38.5 \%)$ & $66(32 \%)$ & $184(41.5 \%)$ & 0.06 \\
\hline 1 to 4 & $371(57.2 \%)$ & $130(63.1 \%)$ & $241(54.4 \%)$ & \\
\hline$>4$ & $28(4.3 \%)$ & $10(4.6 \%)$ & $18(4.1 \%)$ & \\
\hline Hx prior abortion & $476(73.3 \%)$ & $159(77.2 \%)$ & $317(71.6 \%)$ & 0.13 \\
\hline Hx of c-section & $87(13.4 \%)$ & 25 (12.1\%) & $62(14.0 \%)$ & 0.5 \\
\hline Multiple Gestation & $8(1.2 \%)$ & $1(0.39 \%)$ & $7(1.6 \%)$ & 0.426 \\
\hline $\begin{array}{l}\text { Months since last } \\
\text { delivery (mean) }\end{array}$ & 13.7, SD 4.6 & 12.6, SD 4.8 & 14.3, SD 4.5 & $<0.001$ \\
\hline $\begin{array}{l}\text { Weeks gestation } \\
\text { (mean) }\end{array}$ & $\begin{array}{l}18 \text { wOd, SD } \\
16 \text { days }\end{array}$ & $17 w 0 d$, SD14 d & $\begin{array}{r}18 w 3 d, S D \\
16 d \\
\end{array}$ & $<0.001$ \\
\hline 14-16 weeks & $157(24.2 \%)$ & $80(38.8 \%)$ & $77(17.4 \%)$ & $<0.001$ \\
\hline 16-18 weeks & $160(24.7 \%)$ & $56(27.2 \%)$ & $104(23.5 \%)$ & \\
\hline $18-20$ weeks & $163(25.1 \%)$ & $52(25.2 \%)$ & $111(25.1 \%)$ & \\
\hline 20-22 weeks & $162(25 \%)$ & $18(8.7 \%)$ & $144(32.5 \%)$ & \\
\hline 22-24 weeks & $6(0.9 \%)$ & 0 & $6(1.4 \%)$ & \\
\hline
\end{tabular}




\begin{tabular}{r|r|r|r|r}
\hline $24+$ weeks & $1(0.2 \%)$ & 0 & $1(0.2 \%)$ & \\
\hline Pre-op diagnosis & & & & \\
\hline Induced abortion & $570(87.8 \%)$ & $193(93.7 \%)$ & $377(85.1 \%)$ & 0.008 \\
\hline Anomaly & $59(9.1 \%)$ & $9(4.4 \%)$ & $50(11.3 \%)$ & \\
\hline IUFD & $19(2.9 \%)$ & $4(1.9 \%)$ & $15(3.4 \%)$ & \\
\hline PPROM & $1(0.2 \%)$ & 0 & $1(0.2 \%)$ & \\
\hline Follow-up visit & $170(26.2 \%)$ & $49(23.8 \%)$ & $121(27.3 \%)$ & 0.635
\end{tabular}


Table 2: Baseline characteristics and estimated blood loss

\begin{tabular}{|c|c|c|c|c|c|}
\hline & Mean EBL (median) & P-value & $\mathrm{EBL}<250 \mathrm{ml}$ & $\mathrm{EBL} \geq 250 \mathrm{ml}$ & P-value \\
\hline Total population $(\mathrm{N}=649)$ & 124.2, SD 118.8 & & $\mathrm{~N}=590(90.9 \%)$ & $\mathrm{N}=59(9.1 \%)$ & \\
\hline No Oxytocin $(\mathrm{N}=206)$ & $\begin{array}{r}105, \text { SD } 73.8(100 \\
[20-600]) \\
\end{array}$ & $\begin{array}{l}<0.001 \\
(0.004)\end{array}$ & $196(95.1 \%)$ & $10(4.9 \%)$ & 0.01 \\
\hline Oxytocin ( $\mathrm{N}=443)$ & $\begin{array}{r}133.1, \text { SD } 133.9 \\
(100[5-1500]) \\
\end{array}$ & & $394(88.9 \%)$ & $49(11.1 \%)$ & \\
\hline \multicolumn{6}{|l|}{ Race } \\
\hline Asian ( $\mathrm{N}=255)$ & 124.5, SD 112 & 0.95 & $231(90.6 \%)$ & $24(9.4 \%)$ & 0.46 \\
\hline Native $\mathrm{HI} / \mathrm{Pac}$ Is $(\mathrm{N}=276)$ & 128.5, SD 142.6 & 0.57 & $226(81.9 \%)$ & $26(18.1 \%)$ & \\
\hline Black $(n=14)$ & 148, SD 54.8 & 0.33 & $11(78.6 \%)$ & $1(1.7 \%)$ & \\
\hline White $(N=110)$ & 109.7, SD 75.5 & 0.045 & $100(90.9 \%)$ & $5(21.4 \%)$ & \\
\hline Unk/Other $(\mathrm{N}=26)$ & 114.5, SD 78.8 & 0.57 & $21(3.6 \%)$ & $1(9.1 \%)$ & \\
\hline \multicolumn{6}{|l|}{ Parity } \\
\hline $0(N=250)$ & 123.4, SD 104.5 & 0.16 & $226(90.4 \%)$ & $24(9.6 \%)$ & 0.78 \\
\hline 1 to $4(N=371)$ & 121.6, SD 108.8 & & $339(91.4 \%)$ & $32(8.6 \%)$ & \\
\hline$>4(\mathrm{~N}=28)$ & 166.3, SD 272.2 & & $25(89.3 \%)$ & $3(10.7 \%)$ & \\
\hline Prior C-section ( $\mathrm{N}=87$ ) & 154.8, SD 202 & 0.12 & $76(87.4 \%)$ & $11(12.6 \%)$ & 0.25 \\
\hline Mult Gest $(\mathrm{N}=8)$ & 153.1, SD 100.4 & 0.44 & $6(75 \%)$ & $2(25 \%)$ & 0.09 \\
\hline \multicolumn{6}{|l|}{ Gestation } \\
\hline $14-16$ weeks $(N=157)$ & 82.4, SD 100.3 & $<0.001$ & $151(96.2 \%)$ & $6(3.8 \%)$ & $<0.001$ \\
\hline $16-18$ weeks $(N=160)$ & 96.3, SD 62.8 & & $150(93.8 \%)$ & $10(6.2 \%)$ & \\
\hline $18-20$ weeks $(N=163)$ & 124.9, SD 68.6 & & $154(94.5 \%)$ & $9(5.5 \%)$ & \\
\hline $20-22$ weeks $(N=162)$ & $183.2,143.6$ & & $129(79.6 \%)$ & $33(20.4 \%)$ & \\
\hline
\end{tabular}




\begin{tabular}{r|r|r|r|r|r}
\hline $22-24$ weeks (N=6) & 366.7, SD 556.5 & & $5(83.3 \%)$ & $1(16.7 \%)$ & 0 \\
\hline $24+$ weeks (N=1) & & & $1(1007 \%)$ & & \\
\hline Pre-Op Diagnosis & & & & & \\
\hline Induced abortion (N=570) & 121.0, SD 107.2 & 0.24 & $518(90.9 \%)$ & $52(9.1 \%)$ & 0.94 \\
\hline Anomaly (N=59) & 142.1, SD 103.6 & & $53(89.8 \%)$ & $6(10.2 \%)$ & \\
\hline IUFD (N=19) & 166.6, SD 327.8 & & $18(94.7 \%)$ & $1(5.3 \%)$ & \\
\hline PPROM (N=1) & & & $1(100 \%)$ & 0 &
\end{tabular}


Table 3: Complications related to oxytocin use

\begin{tabular}{r|r|r|r|r} 
& \multicolumn{1}{|l|}{ Total } & No Oxytocin & \multicolumn{1}{l|}{ Oxytocin } & P-value \\
\hline & $\mathrm{N}=649$ & $\mathrm{~N}=206(31.7 \%)$ & $\mathrm{N}=443(68.3 \%)$ & \\
\hline $\begin{array}{r}\text { Intraoperative } \\
\text { complications (total) }\end{array}$ & $30(4.6 \%)$ & $9(4.4 \%)$ & $21(4.7 \%)$ & 0.579 \\
\hline Perforation & $2(0.31 \%)$ & 0 & $2(0.45 \%)$ & \\
\hline Hemorrhage & $14(2.2 \%)$ & $2(0.97 \%)$ & $12(2.7 \%)$ & 0.471 \\
\hline Cervical Laceration & $5(0.77 \%)$ & $2(0.97 \%)$ & $3(0.68 \%)$ & 0.685 \\
\hline Repeat Suction & $1(0.15 \%)$ & $1(0.49 \%)$ & 0 & 0.52 \\
\hline Other & $3(0.46 \%)$ & 0 & $3(0.68 \%)$ & 0.758 \\
\hline $\begin{array}{r}\text { Follow-up } \\
\text { Complications }\end{array}$ & $5(0.77 \%)$ & $4(1.94 \%)$ & $1(0.23 \%)$ & 0.025
\end{tabular}


Table 4: Logistic Regression: Relationship between gestational age \& EBL $\geq 250 \mathrm{ml}$

\begin{tabular}{rr|r|r|r} 
& \multicolumn{1}{|l|}{ AOR* } & \multicolumn{1}{l|}{$95 \% \mathrm{Cl}$} & $\mathrm{p}$-value \\
\hline Gestational age (weeks) & & 1.31 & $1.15-1.50$ & $<0.001$ \\
\hline$<18$ weeks & 1 & & \\
\hline$\geq 18$ weeks & 2.47 & $1.34-4.53$ & 0.004 \\
\hline & & 1 & & \\
\hline $14-16$ weeks & $16-18$ weeks & 1.58 & $0.56-4.48$ & 0.392 \\
\hline $18-20$ weeks & 1.37 & $0.47-3.97$ & 0.566 \\
\hline $20+$ weeks & 5.46 & $2.15-13.87$ & $<0.001$ \\
\hline & & & & \\
\hline Oxytocin use & & 1.61 & $0.77-3.37$ & 0.203
\end{tabular}

*Adjusted for oxytocin use and gestational age 


\section{REFERENCES:}

1. Jones RK, Jerman J. Abortion incidence and service availability in the United States, 2011. Perspect Sex Reprod Health 2014,46:3-14.

2. Pazol K, Creanga AA, Burley KD, Jamieson DJ. Abortion surveillance - United States, 2011. MMWR Surveill Summ 2014,63:1-41.

3. Rolnick JA, Vorhies JS. Legal restrictions and complications of abortion: insights from data on complication rates in the United States. J Public Health Policy 2012,33:348-362.

4. Kerns J, Steinauer J. Management of postabortion hemorrhage: release date November 2012 SFP Guideline \#20131. Contraception 2013,87:331-342.

5. Peterson WF, Berry FN, Grace MR, Gulbranson CL. Second-trimester abortion by dilatation and evacuation: an analysis of 11,747 cases. Obstet Gynecol 1983,62:185-190.

6. Altman AM, Stubblefield PG, Schlam JF, Loberfeld R, Osathanondh R. Midtrimester abortion with Laminaria and vacuum evacuation on a teaching service. J Reprod Med 1985,30:601-606.

7. Prager SW, Oyer DJ. Second-trimester surgical abortion. Clin Obstet Gynecol 2009,52:179-187.

8. Fuchs AR, Fuchs $F$, Husslein $P$, Soloff MS. Oxytocin receptors in the human uterus during pregnancy and parturition. Am J Obstet Gynecol 1984,150:734741.

9. Kimura $T$, Takemura $M$, Nomura $S$, Nobunaga $T$, Kubota $Y$, Inoue $T$, et al. Expression of oxytocin receptor in human pregnant myometrium. Endocrinology 1996,137:780-785.

10. Lauersen $\mathrm{NH}$, Conrad P. Effect of oxytocic agents on blood loss during first trimester suction curettage. Obstet Gynecol 1974,44:428-433.

11. Nygaard $\mathrm{IH}$, Valbo $\mathrm{A}$, Heide $\mathrm{HC}$, Kresovic M. Is oxytocin given during surgical termination of first trimester pregnancy useful? A randomized controlled trial. Acta Obstet Gynecol Scand 2011,90:174-178. 
12. Micks E, Edelman A, Botha R, Bednarek $P$, Nichols $M$, Jensen JT. The effect of sevoflurane on interventions for blood loss during dilation and evacuation procedures at 18-24 weeks of gestation: a randomized controlled trial. Contraception 2015.

13. Institute G. Abortion incidence and access to services in the United States, 2008. Perspectives on Sexual and Reproductive Health 2011,43:41-50.

14. Pazol K, Creanga AA, Zane SB, Burley KD, Jamieson DJ, Centers for Disease C, et al. Abortion surveillance--United States, 2009. MMWR Surveill Summ 2012,61:1-44. 